\title{
Developing Global and Technological Education Standards of Social Education Curriculum in Mid-Stage in Jordan
}

\author{
Mahmoud Sulaiman Bani Abdelrahman ${ }^{1}$, Eid El-Subhieen ${ }^{1} \&$ Mustafa Jwaifell $^{1}$ \\ ${ }^{1}$ Department of Curriculum and Instruction, Faculty of Educational Sciences, Al- Hussein Bin Talal University, \\ Jordan \\ Correspondence: Mahmoud Sulaiman Bani Abdelrahman, Department of Curriculum and Instruction, Faculty of \\ Educational Sciences, Al- Hussein Bin Talal University, Jordan. E-mail: Abugaith66@yahoo.com
}

Received: May 3, 2012 Accepted: May 22, 2012 Online Published: August 30, 2012

doi:10.5539/ass.v8n11p219

URL: http://dx.doi.org/10.5539/ass.v8n11p219

\begin{abstract}
The study aimed at developing global and technological education standards of social education curriculum in the Mid-stage in Jordan. The researchers developed an instrument included (31) items of the main concepts and values of the global and technological education. Results after analyzing curricula indicated that the curricula did not take into account the concepts and values of the global and technological according to the standards that have developed. The study included details of the standards and its statistical analyses. Recommendations were given to take use of these standards in the mid-stage by decision makers and more researches in other curriculum domains.
\end{abstract}

Keywords: global education, technological education, curriculum standards, content analyses

\section{The Background of the Study}

With regard of their important influence on learners' acquiring skills and morals, social studies curricula play a significant role in constructing a positive and good citizen (physically, mentally, psychologically, socially, and spiritually). Thus, the educational research encyclopedia defines social studies as: parts of social sciences that serve educational purposes. In this sense, 'Social Studies' concerned with human and his interaction with the natural and social environments. It also includes certain skills, morals and trends that are necessary in building up an active and effective member in society. In addition it concerned with natural and human phenomena, thus it helps in building the individual's ability to acquire knowledge in different fields as well as improving desired behavioral trends (Tete, 2002, p. 15).

The significance of social studies curricula appears basically in being a source of social learning and education in which human is the center of the study. In addition to their importance in evoking the learners' interest in present social conflicts and their aware participation in facing their society's social, economic, political, scientific, and technological problems. They also develop scientific thinking and help learners understand generalizations that are based on scientific assumptions these curricula help understand the concept of universal understanding and realizing our position within this world and work on proving our reality (Assakran, 2000, pp. 22-23).

Social studies curricula also aims at evoking loyalty among people along with learners' abilities to analyze, think, conclude and criticize positively on one hand, and realize important concepts like: cooperation, positive competition, and development and change, on the other hand. Other aims include reinforcing the concept of universal cooperation based on mutual-respect, as well as appreciating the human efforts and achievements, old and new ones (Laughlin \& Hartoonian, 1995, p.18).

Referring to mid-stage social studies curricula, some distinctive objectives include respecting human rights, practicing equality and justice among people, accepting individual differences in different cultures and environments, appreciating the importance of science and learning in the life of individuals and societies and developing their civilizations, and realizing the necessity of technology and modern equipments in proving production and achieving people's needs. Other objectives are concerned with building knowledge about one's self, family, school, neighborhood, and surrounding environment, as well as acquiring skills of observing, listening, drawing simple plans of the things that one is using, along with the ability to sense place and time and 
realize their effect on the life of individuals, groups and cultures (Abu Hilu et al, 2004, pp. 29-30).

Supposedly, social studies curricula should work on achieving convergence among nations, and building universal understanding through introducing learners to the world and its new and old political systems, identifying the concept of mutual dependence between people, and introducing them to international organizations such as the UNESCO, and others. These curricula should also balance between national objectives on one hand and international objectives on the other hand, in order to give us the chance to emerge in this world and prove that we are part of human nations on earth (Tete, 2002, pp. 30-36).

The global education concept refers to the kind of education oriented to improve principles of cooperation and peace among people, in addition to developing good relations among nations having different social and political activities. Such objectives are also concerned with those principles declared by the United Nations Charter and the International Declaration of Human Basic Rights and Freedoms (Hamida et al, 2000, 152). Global education is "a combination of different fields that proved students with important universal views, preparing them for living in a futuristic demanding world of shared horizons." (Laughlin \& Hartoonian, 1995, p. 263)

Global education tends to understand the world and any occurring cultural, political, scientific, technological, social, and economic interactions. Thus, the Jordanian Ministry of Education realizes the importance of global education. This appears clearly in the Jordanian Constitution, Education article number (4) (1994) states the necessity of improving national basics and emphasizing the importance of international understanding, based on justice, equality, freedom and positive participation in the universal civilization, in addition to preserving environment and improving its resources (The Ministry of Education, 1994).

It is important also to refer to Islam, which shows a great concern regarding global education. In fact many Quranic verses in "Alquran Alkareem" and Prophetic speeches honor humans regardless their color, race, gender, or even religion; "indeed We have honored the Children of Adam, and We have carried them on land and sea, and have provided them with At-Taiyibât (lawful good things), and have preferred them above many of those whom We have created with a marked preference" (AL-Quran Alkareem, Esra, verse,70) (Esra' . Islam is also constructed upon balance, moderation, and facilitating; "Thus We have made you [true Muslims - real believers of Islâmic Monotheism, true followers of Prophet Muhammad ( peace be upon him) and his Sunnah (legal ways)], a Wasat (just) (and the best) nation, that you be witnesses over mankind[] and the Messenger Muhammad( peace be upon him) be a witness over you. And We made the Qiblah (prayer direction towards Jerusalem) which you used to face, only to test those who followed the Messenger Muhammad( peace be upon him) from those who would turn on their heels (i.e. disobey the Messenger). Indeed it was great (heavy) except for those whom Allâh guided. And Allâh would never make your faith (prayers) to be lost (i.e. your prayers offered towards Jerusalem). Truly

Allâh is full of kindness, the Most Merciful towards mankind." (AL-Quran Alkareem, Baqarah, verse, 143).

Islam has also raised great principles for the sake of humanity, such as peace and justice, under which all people are equal. Being for the good of all humans, these principles come under the wide umbrella of religions and parties. Prophet Mohammad, peace be upon him, said: "you people, you all have one God and one Father, therefore race and color are of no matter, only fear. For Allah, the best of you is who fears Him the most" (Alasqalani, 1995, ch. 6). In addition to this, Islam identified its essential aim as spreading mercy and good benefits among all people; "And We have sent you Muhammad ( peace be upon him) not but as a mercy for the 'Alamîn (mankind, jinns and all that exists). (AL-Quran Alkareem ,Al-Anbyia', verse, 107)

Life is given a precious value in Islam, so killing is a crime. Even in wars, it is forbidden to kill citizens or destroy their properties, women, little children, old people, and students. Allah emphasizes the importance of humans' life for it is necessary to keep world progress; "Because of that We ordained for the Children of Israel that if anyone killed a person not in retaliation of murder, or (and) to spread mischief in the land - it would be as if he killed all mankind, and if anyone saved a life, it would be as if he saved the life of all mankind. And indeed, there came to them Our Messengers with clear proofs, evidences, and signs, even then after that many of them continued to exceed the limits (e.g. by doing oppression unjustly and exceeding beyond the limits set by Allâh by committing the major sins) in the land!." (AL-Quran Alkareem, Alma'idah, verse, 32). These verses and many others from Quran and Prophet's speeches prove that all the principles and concepts of the global education are an authentic part of the Islamic belief and education.

The concept of scientific education refers to an educational dimension that aims at improving learners' knowledge, skills, and principles towards science and learning technology, in addition to preparing them to be able to react positively with any technological and scientific development trends in different fields of life. On being so, many advanced world countries have included science and technology in their social studies curricula. 
In U.S.A in 1994, for instance, the National Council for the Social Studies has come up with some criteria and standards for the social studies curricula of all educational levels, including the issue of science, technology, and society (National Council for the Social Studies NCSS, 1994, pp. 5-17).

Including science and technology issues in school curricula help create positive tendencies towards science and its processes, improves learners' intellectual tendencies and positive interaction with science and technology outcomes, and provides the opportunity to get better life quality. Some of the issues tackled by global, scientific and technological education of the mid-stage include subjects like; nutrition, poverty and famine sources, air and atmosphere, power and water resources, human health, minerals, animals and plants resources, nuclear power, technology, medical, scientific, industrial and agricultural production processes, in addition to many other subjects that should be included in the curricula, complementarily along with the development of science and technology which both affect, positively or negatively, these issues (Abu Sharar, 2010, p. 18).

Since the social studies curricula are connected totally with life and are centered by the human and his relations with individuals and groups, they help learners understand themselves and others, and adapt to living with them based on the kind of values, concepts, morals, trends, and interests provided by the curricula (Mubarak, 1991, p. 152)

As stated above, including aspects and principles of scientific and global education within the social studies curricula helps create positive changes in learners' morals and orientations. Thus, society and learners' needs, aims, hopes, and ambitions change over time as well as sways of thinking along with world's fast changes. Based on this, one of the researchers has referred to the connection between universal issues and issues related to science and technology. Such connection is represented by population increase, air and atmosphere, water resources, earth and minerals, human health and power (Abu Sharar, 2010).

During the last centuries, some global, scientific and technological issues have appeared and, as a result, great universal and critical conflicts raised; such as environmental pollution, dangerous diseases, drugs and smoking, climate changing, global warming, and many other universal issues that were mainly resulted by the development of science and technology. In this world, old principles and standards were replaced by new morals, concepts and standards, imaginative inventions are there in different fields of life, high-speed development in communication technology takes place, mutual dependence among individuals and societies increases more and more along with the gap between rich and poor countries economically, technologically, scientifically and educationally. In such a world also, conflicts and struggles tend to spread out which threatens humanity, especially after the emergence of nuclear, biological and chemical weapons. In such a world, power of international organizations such as the United Nations, the Security Council and others, their power tend increase (Ibrahim, 2000, p. 29).

There comes the turn of the education and learning systems to face these challenges in a high professional and scientific way. Therefore, it is important to include social studies curriculum since it is more comprehensive of issues related to society and individuals, so it would help find alternatives to such struggles. In their book, Attal and his colleagues have pointed that effective school curricula are those which prepare generations to live in the present effectively, face future challenges including the mental and cultural ones, challenge scientific and technological failure, as well as facing the Zionist challenge (1993. Pp. 740-742).

For global education, the year of (1974) is considered to be a turning point, because the general forum of UNISCO has declared in its second meeting what is known as the recommendation of education for the sake of universal understanding, peace and cooperation, human rights and basic freedoms, respecting cultures and other nations, developing individual abilities to communicate with others, improving the universal awareness towards mutual dependence among nations, and preparing the individual to participate in solving local and international problems; especially those concerned with regional conflicts, racial discrimination, and malnutrition (Le Roux, 2001, p. 12).

The process of developing teaching-learning standards for the educational materials is one phase of developing the educational process to proceed along with the decades' changes and progresses. As a result, many world countries have derived and identified certain standards for each teaching material including social studies curricula as well, in order to use them in planning, designing, constructing, evaluating, and developing curricula. The NATIONAL Centre of Social Sciences(NCSS) in U.S.A published certain approaches including some social studies standards to be used in the last decades of the previous century and they are still used in U.S.A and a lot of other countries like Australia. The eighth approach concerned with issues related to science, technology, and society. In fact, this approach tackles certain questions like: is current technology better than the old one? Why? The question of technology development and its effect on social change, how to adapt with the developments and 
changes resulted from technology? How to use values and traditions in facing technology and its results? The ninth approach, on the other hand, discussed issues of Global Connections. It explores universal issues and how to deal with them such as the struggles between national and international concerns, health, environment, human rights, economic competition, independence, racial discrimination, international allies, and universal communications among human societies (NCSS, 1994, pp. 3-15).

The process of developing school curricula is one process of creating curriculum that comes after assessment. Through this process, for each one of the curriculum's factors (objectives, content, activities and methods and evaluation) strength points are reinforced while weaknesses are treated. Then, it is important to have the process of assessing and developing social studies curricula completed with regard of teaching-learning standards that include experiences with which learners interact. Such experiences should provide the learner with the opportunity to develop his mind, intellect, and exploring abilities. They also should build the learners' knowledge, values, orientations, and skills concerning global, scientific and technological education; building them in a way that gives the learner a chance to understand what he acquired and, highly, apply this to his life as possible as he can (NCSS, 1998, pp. 4-10).

The important question now is "what are the global, scientific and technological education principles, values and concepts? Are they included in the mid-stage social studies curricula in Jordan? Answering such questions requires to be based on scientific bases, and this is exactly what the researchers try to achieve in this study. In other words, there must be a process of assessing mid-stage social studies curricula in Jordan, with regard of the developed standards that include global and technological education concepts, values and principles. This assessment demands measuring the extent of considering these concepts and values, identifying it statistically using 'content analysis' method.

Many of the preceding local and universal studies have discovered the lack of global education concepts and values in social studies curricula; like the studies of: Clarke (1990), Fleming (1991), Jawarneh et al (2009). While other studies represented a suggestion or a conception to what should be included of global education concepts and values in social studies curricula, like the studies of: Aljazzar (1989), Archibald (2001), and Almoosa (2005). Some studies were concerned with human rights concepts in mid-stage social studies curricula like: Williams (2002) and Yamasaki (2000).

Some other studies like Kirman (1992), Shee (2005), and Abu Sharar (2010) have tackled the introduction to science, technology and values in social studies curricula. On the other hand, many results in local studies pointed at the importance of modernizing and developing social studies curricula in Jordan in order to go in parallel with current developments, as Ababna (2003) and Alebraheem (2003). Assagheer's study (2003) has analyzed the content of citizenship article of third and fourth grades in Britain aiming at recognizing the kind of concepts, values, objectives, and methodology it includes, the way of presenting the idea, and the dominant tendencies found in this article.

After presenting the previous studies and exploring notices about them, this study is a distinguished one from the preceding ones, for it is concerned with: developing certain standards, global, scientific and technological education for mid-stage social studies curricula in Jordan using references, sources and available previous studies. It combines global education concepts and values on one hand, with concepts and values of technological education on the other hand also uses 'content Analysis' method to evaluate mid-stage social studies curricula in Jordan.

\section{The Problem of the Study}

The objective of this study is developing global and technological education standards of social education curriculum in the Mid-stage in Jordan, then evaluating these curricula with regard of these standards using the content analysis method to see to what extent these standards are considered in these curricula.

\section{Questions of the Study}

The study answered the following questions:

a) What concepts, principles and values concerned with global and technological education that are significant to mid-stage social curricula in Jordan?

b) To what extent are these concepts, principles and values of the global and technological education are considered in the mid-stage social books in Jordan?

\section{Significance of the Study}

The following points underline the significance of the study 
a) Developing certain global and technological standards with all what it includes of principles, concepts and values for the mid-stage social curricula, and using these standards as a tool to measure the consideration of these standards in mid-stage social curricula.

b) This study of the few studies that combine global education concepts and values along with those of technological education with regard of certain standards under one approach.

c) Evaluating mid-stage social curricula with regard of global and technological education concepts and values, using content analysis method.

d) The necessity of adapting to global, technological and scientific changes along with the updated demands, through developing the curricula based on contemporary scientific vision. Thus this study helps providing the opportunity for other similar studies on several school levels.

\section{Limitations of the Study}

The study is basically limited to the following:

a) Global and technological standards including concepts, values and principles for the mid-stage social curricula in Jordan, that were achieved and included in the instrument of the study by the researchers; based on which social and national curricula were evaluated.

b) Evaluating mid-stage social and national curricula in Jordan, using the content analysis method.

\section{Definition of Terms}

Mid-stage education: is considered by the researchers the fifth to eight grades in the Ministry of Education Schools in the Hashemite Kingdom of Jordan.

Mid-stage Education Social and National Education Curricula in Jordan: those documentaries including general and particular outcomes of (national and civil education, history and geography) in the mid-stage education that were recommended by the Education Council announcement number 44/2004, in 2/7/2004.

Global Education: is the kind of education oriented towards understanding the world and whatever cultural, political, scientific, technological, social, and economical interactions occurring, as a way to spread the culture of tolerance, love, mutual respect, cooperation and peace, in addition to spreading human rights and basic freedoms.

Technological Education: an educational tendency aims at developing learners' knowledge, skills, values, and tendencies towards science, learning and technology, so they will be able to interact positively with scientific and technological development in the different fields of life.

Global, Scientific and Technological Education Criteria: the kind of teaching-learning experiences that are expected to be highly used by the learner to acquire knowledge, skills, values, and tendencies concerning the approach of global, scientific and technological education, that were included in specific obvious sentences and paragraphs developed by the two researchers through referring to national and international educational literature.

Evaluating National and Social Education Curricula: measuring the extent to which these school books consider the criteria found in the study tool, using "Content Analysis" method.

\section{Methodology and Procedure of the Study}

\subsection{Methodology of the Study}

In this study, the researchers used analytical, descriptive method, since this method is suitable to this kind of studies. The following is a presentation of the population of the study sample, instrument and procedures:

\subsection{Population of the Study}

The sample of the study consists of the population represented by the curriculum documentaries including general and particular outcomes of (national and civil education, history and geography) in the mid-stage education that were recommended by the Education Council announcement number 44/2004,dated in the 2nd of July ,2004.

\subsection{Instrument of the Study}

The instrument of the study consists of teaching-learning criteria that includes important concepts and values of what concerned with global, scientific and technological education in primary-stage social and national education books. These criteria were developed, constructed, identified, validated, and used as a tool to analyze 
the mid-stage social and national education curricula. The researchers have come up with them throughout the following:

a) Referring to theoretical literature, main and secondary sources and references, previous studies, and tools that are concerned mainly with the universal criteria.

b) Constructing a list of the criteria that are concerned with global, scientific and technological education of social and national education books, using them as a tool to analyze the content of mid-stage books content, after checking their validity and reliability.

c) Checking its validity through showing it to qualified specialists in social studies curricula. The instrument eventually, consisted of 31 criteria including important concepts, principles and values concerning global, scientific and technological education.

\subsection{Procedures of the Study}

\subsubsection{To Answer the First Question}

"What concepts, principles and values concerned with global and technological educations that are significant to mid-stage social curricula in Jordan?"

To answer this question, the same previous steps that were used to construct the instrument of the study. In fact they were based on the standards concerning the approach of global, scientific and technological education of social and national educational curricula. These standards were included within the instrument of the study in its final conception as an answer to this question. They were thirty one standards including concepts, values and principles which tackle the approach of global, scientific and technological education.

7.4.2 To Answer the Second Question of the Study

"To what extent are these concepts, principles and values of the global and technological education are considered in the mid-stage social books in Jordan?"

Mid-stage social and national education curricula were evaluated by using 'Content analysis' method to figure out how much they consider concepts, values and principles of global, scientific and technological education, following these steps:

a) Identifying the following:

The analysis objective: measuring the extent to which the concepts, values and principles of the global educational technology in the mid-stage in Jordan considering, scientific and technological education social and national education books in Jordan.

The analysis population: mid-stage social and national education curricula mid-stage in Jordan.

The analysis categories: concepts and values and principles included within the standards concerning the approach of global and technological education.

The analysis unit: word, sentence, and meaning.

b) Analyzing the sample of the study represented in mid-stage social and national education curricula twice in a three-week period of time. Then reanalyzing it by specialists of social studies curricula and methodology. To check the reliability, Holsti Constance formula was used:

Coefficient $=$ number of correspondence times of 1st and 2nd analysis X 100 (Correspondence times + difference times)

The following table shows Coefficient through time and through people:

Table 1. Coefficient through time and through people

\begin{tabular}{cc}
\hline Reliability through people & Reliability through time \\
\hline 84 & 87 \\
\hline
\end{tabular}

c) Using frequencies and percentages to gather data concerned with answering the second question to identify and discus the results.

\section{Results and Discussions}

\subsection{The First Question}

"What concepts, principles and values concerned with global and technological educations that are significant to mid-stage social curricula in Jordan?" 
The researchers answered this question by reviewing the literature, the main sources and relevant secondary criteria of social studies, research and studies on the subject, as well as referring to the philosophy of education in Jordan and its offspring of the objectives of Education, references and sources. As result, thirty one standards were developed for the content of mid-stage social and national education curricula in the field of global, scientific and technological education. These standards are shown in table 2 in the body of the study.

What makes the study distinctive is the way it combines concepts, values and principles of global education on one hand with those of technological and scientific education on the other hand. The researchers believe that both approaches could not be separated from each other. Global education and communication could never be done independently from technology and science. The researchers also believe that interacting with the content of this axis in mid-stage social and national education curricula is very important, for the whole world is but a combination of different cultures and religions. Therefore learners need to be able to deal with universal issues such as: keeping of health and environment, human rights, economic, scientific technological and economical competition, independence, ethnic and racial conflicts, and international alliances, in order to spread love and tolerance, mutual respect, cooperation and peace, understanding the growing importance of global communication, and being aware of the conflict between national and global concerns.

Technology and science that support global education are necessary to live in these days, and cannot be separated from Twenty-First century global education in particular. Modern technology in fact has turns the world into a small village, and it is necessary for the learners to acquire knowledge, skills, values and trends that are tackled through some questions as: how does the human get to science, knowledge and discoveries? How science and knowledge lead to the development of technology and equipments? Is modern technology better than the old one, and why? How did modern technology change the social scale? How communities can adapt to the context of rapid change? How technology can be organized so that it benefits the largest possible number of people? How can we keep the constant of the nation's ideologies and values in the midst of this change? How do technology and science contribute to the rapprochement between peoples, and find solutions for many global issues?

Evaluating and developing social studies curricula with regard of organized teaching-learning standards is one of the main aspects for the development of the educational process in recent decades to keep pace with the spirit of the age and its requirements and variables. These cognitive and sentimental standards were designed to include experiences with which learners could interact, provide the opportunity to develop their minds, thoughts and abilities, and to let them acquire knowledge, values, attitudes and skills theoretically and practically in the field of global, scientific and technological education so they can understand what they have acquired and apply it to their lives as much as they can.

\subsection{The Second Question of the Study}

"To what extent are these concepts, principles and values of the global and technological education are considered in the mid-stage social books in Jordan?"

After the completion of constructing the analysis instrument which is the criteria that focus on global, scientific and technological education, and are important for the mid-stage social and national education books, these books have been evaluated using 'Content analysis' method. The process of analysis has revealed the results described in Table 2.

Table 2. Frequencies and percentages of the availability of global, scientific and technological education axis in mid-stage social and national books in Jordan

\begin{tabular}{|c|c|c|c|}
\hline No. & $\begin{array}{l}\text { Criteria concerning the approach of global, scientific and } \\
\text { technological education. }\end{array}$ & Frequencies & percentage \\
\hline 1 & $\begin{array}{l}\text { Realizing the importance of cultural positive development, and } \\
\text { benefitting from other cultures. }\end{array}$ & 1 & 0.018 \\
\hline 2 & Analyzing how technology affects positively the national economy. & 3 & 0.05 \\
\hline 3 & $\begin{array}{l}\text { Analyzing the effect of technology on communication, knowledge, } \\
\text { and global connection. }\end{array}$ & 2 & 0.04 \\
\hline 4 & Explaining how technology affects people's life, beliefs and thoughts. & 0 & 0.00 \\
\hline 5 & $\begin{array}{l}\text { Believing in the importance of peace, tolerance, and freedom of } \\
\text { belief. }\end{array}$ & 2 & 0.04 \\
\hline 6 & $\begin{array}{l}\text { Realizing the importance of using modern technology in nations' } \\
\text { progression and prosperity. }\end{array}$ & 1 & 0.018 \\
\hline
\end{tabular}


Realizing technology's role in cultures transference, and rapprochement among people.

Rejecting terrorism, discrimination, and violence in solving local and universal conflicts.

Realizing the importance of democracy and respecting minorities' rights.

Explaining the importance of mutual dependence between individuals constitutes, and countries in achieving needs.

Realizing the importance of international organizations and constitutions in keeping international peace and human rights.

Recognizing the problems of using technology in people's life, and suggests solutions.

Realizing that civilization development of any nation is concerned

13 with its culture progression through benefitting from other cultures and the updated technology.

Recognizing international and local moral and lawful standards that control using technology, like the law of environment preservation.

Realizing dangers resulted from Arab nation's technological and scientific regression, in addition to its effect on its future and relationship with other countries.

Explaining with examples how to use technology in turning natural environment into serving human.

17 Showing interest in universal and Arab issues and events.

18 Demonstrating, with examples, conflict and cooperation among nations and associations.

19 Realizing the importance of respecting humans and their rights.

Explaining how to use technology in universal communication and cooperation such as combating diseases and building floodgates.

Recognizing international critical conflicts and issues like: pollution, lack of resources. Disasters, crime, drugs and terrorism.
Knowing how societies are affected by other countries' activities like: environmental pollution and the conflict of water and rivers.

Exploring the effect of language, beliefs, culture, art and music in nations' convergence and divergence.

Analyzing the reasons of conflict among countries on one hand and those of peace on the other hand.

Appreciating the role of Arab and Islamic culture in seeking knowledge and positive communication with other nations.

Recognizing the world and the country's trends towards economic openness and secularism.

Concluding from history the negative effects of universal clash and wrong usage of technology in destroying human life.

Appreciating the role of educational constitutes in developing and changing society positively as well as serving individuals.

Rejecting all wrong beliefs, illusions, and appreciates the role of science, scientists and researchers in serving humanity.

Expressing rejection of all kinds of discrimination concerned with color, sex, religion or culture.

Suggesting methods to develop science and technology in developing countries.

Total 
Table 2. shows the following results:

a) There are thirteen standards where there is no frequency; $(4,7,11,13,14,15,17,19,22,23,24,26$, and 31). While five standards reflect only one frequency $(1,6,9,18$, and 27$)$.

b) Nine standards reflect (2-3) frequencies only; (2, 3, 5, 8, 20, 21, 25, 29, and 30).

c) Only four standards reflect five and more of frequencies; (10,12, 16, and 28).

This result indicates clearly that the issue of global, scientific and technological education in mid-stage education has not received adequate attention by the social books designers, and perhaps the reason for this is the lack of awareness of the importance of this dimension by those who design books of social and national education curricula, in addition to focusing only on topics such as service institutions and several historical and geographical issues. Though these issues are important, but school curricula and books designers can integrate concepts and values of global, scientific and technological education complementarily within these issues and titles.

\section{Recommendations}

In the light results of the study, the researchers recommended the following:

a) Researchers and those who work on developing mid-stage social studies curricula should benefit from this study, especially in the field of constructing global, scientific and technological education standards.

b) Reconsidering mid-stage social and national education curricula in Jordan with regard of the study results, and of what makes them considering the criteria of global, scientific and technological education.

c) Considering contemporary global developments and trends, in addition to depending on merging between the progressions in different fields on one hand, with the society's value, traditions, needs and national and intellectual perspectives on the other hand. And finally, working more on relevant studies in different school stages.

\section{References}

Ababna, D. (2003). An Evaluation of Geography Curricula for the Upper Basic Stage in the Light of the Global Standards. Unpublished Doctoral Dissertation, Yarmouk University, Irbid, Jordan.

Abu Hilo, Y. Merai, T., \& Keraisha, A. (2004). Curricula and Methods of Teaching Social Studies (1st ed.). Open Arab University, Al-Safat, Kuwait.

Abu Sharar, Y. (2010). Issues of Science, Technology and Society in Geography Textbook of the 2nd Secondary and their Level of Understanding. Unpublished M. A Thesis, Islamic University, Gaza.

Al-Jazzar, N. (1989). Developing History Textbook in the Basic 2nd Stage in the Light of the International Understanding. Unpublished Doctoral Dissertation, Ain Shamas University, Egypt.

Almoosa, J. (2005). Developing the History of Curricula of the Upper Basic Stage in Jordan in the Light of Global Educational Principles and Measuring its Effect on Teachers' Attitudes Towards History Subject. Unpublished Doctoral Dissertation, Amman Arab University for Higher Studies, Amman, Jordan.

Al-Quran Al-Kareem. Holy Quran.

Al-Tal, S. et al. (1993). Reference in Educational Principles (1st ed.). Dar Al-Shroog Publishing HOUSE, Amman, Jordan.

Archliblad, D. B. (2000). Global Education: An Alternative Program of study for Progressive Learning. Dissertation Abstracts International, 39(2), 324.

Asqalani, I. A. (1995). Alisabeh fee Tameeze AlSahabah. International Book House, Beirut, Lebanon.

Assagheer, A. (2003). Analytical Reading to Content of Citizenship paper for 3rd and 4rth Graders in United Kingdom. Building Curricula Seminar, College of Education, King Saud University, Riyadh, Saudi Arabia.

Assakran, M. (2000). Methods of Teaching Social Studies (1st ed.). Dar AlSharoog Publishing House, Amman, Jordan.

Azeez, M. (2000). An Encyclopedia of Educational Curricula. Anglo Egyptian Bookshop. Cairo, Egypt.

Clarke, G. (1990). A Curriculum in Elementary Social Studies (Proposal to Revise). ERIC NO. ED 31866.

Fleming, D. (1991). Social Studies and the Report of the Education: California, New York, Commission on Social Studies. ERIC NO. National ED 340631. 
Hamida, I., Arafah, S., Qurashi, H., Shahat, H., \& Qurashi, A. (2000). Teaching Social Studies in Public Schools. Zahraet AlSharq Bookshop, Cairo, Egypt.

Holsti, R. (1969). Content Analysis for the Social Sciences and the Humanities. Addison Wesley Publishing Company.

Ibrahim, R. (2003). An Evaluation of Social Studies Curricula in the Secondary Stage in Jordan: Towards a way to be Developed. Unpublished Doctoral Dissertation, Yarmouk University, Irbid, Jordan.

Jawarneh, M., Al-Mousa, J., Shediafat, S., \& Eiyadat, W. (2009). Developing an Educational Unit in the Light of the Global Educational Priciples and its Effect of English Grade Jordanian Students' Achievement in History. Journal of Human Sciences, (42).

Kirman, J. (1992). Values, Technology, and Social Studies. Mc Gill Journal of Education, 27(1), 5-18.

Laughlin, M., \& Hartoonian, H. (1995). Challenges of Social Studies Instruction in Middle and High Schools. New York: Harcourt Bruce College Publisher.

Le Roux, J. (2001). Re-examining Global Educations relevance beyond 2000. Research in Education, 65, 11-70.

Ministry of Education in Jordan. (1994). Laws, Systems and Educational Instructions. Administrations of Laws Affairs, Amman, Jordan.

Mubarak, F. (1991). The Needed Social Values in the Second Cycle Students in the Basic Schools and the Role of Social Studies Curricula in Improving Students. Journal of Egyptian Community of Curricula and Methods of Teaching, 133-177.

National Council for the Social Studies. (1994). Expectations of Excellence: Curriculum Standards for Social Studies.

National Council for the Social Studies. (1998). Expectations of Excellence: Curriculum Standards for Social Studies (3rd ed.). Bullet in 89, Washington. D.C.

Shee, H. (2005). Content analysis of Books of World History in the Light of the Entrance of STS in Secondary School in the United of America On 22-2-2009. Retrieved from http://proquest.Umi.com

Tete, M. (2002). Social Studies: Nature, Objectives, Methods (1st ed.). AlMaseerah Publishing and Printing House, Amman, Jordan.

Williams, R. (2002). Alberta Social Studies Textbooks and Human Rights Education. Dissertation Abstracts International, 1(40), 1-23.

Yamasaki, M. (2000). Human Rights Education and Elementary School Level: Case Study. Dissertation Abstracts International. 